\title{
MODELING THE GROUNDWATER LEVEL CHANGES IN AN AREA OF WATER RESOURCES OPERATIONS
}

\author{
${ }^{1}$ Michaela ČERVEŇANSKÁ, ${ }^{2}$ Dana BAROKOVÁ, ${ }^{3}$ Andrej ŠOLTÉSZ \\ Department of Hydraulic Engineering, Faculty of Civil Engineering \\ Slovak University of Technology in Bratislava, Radlinského 11, 81005 Bratislava, Slovakia \\ e-mail: ${ }^{1}$ michaela.cervenanska@ stuba.sk, ${ }^{2}$ dana.barokova@stuba.sk, ${ }^{3}$ andrej.soltesz@ stuba.sk
}

Received 18 December 2015; accepted 9 May 2016

\begin{abstract}
The water sources located on the inland islands on the left side of the Danube River as well as water sources located on the right bank of the Danube River in the Pečniansky forest have an irreplaceable function in terms of supplying the population in Bratislava with drinking water. There are 80 wells in these mentioned areas operated by the Bratislava Water Company. In order to maintain the actual functions of the water resources, it is therefore necessary to assess the impact of the proposed construction of the multi-purposed structure 'Hydraulic structure Bratislava - Pečniansky forest' on these water sources.
\end{abstract}

Keywords: Drinking water, Groundwater flow modeling, Groundwater level, TRIWACO software, Water sources in Bratislava

\section{Introduction}

The main source of water for the Bratislava urban area, which should be satisfactory in terms of its quality and quantity, is groundwater from the aquifer of the Danube River sediments. They are the water sources located on the Sihot' and Sedláček inland islands, which are on the left side of the Danube River as well as the water source located on the right bank of the Danube River in the Pečniansky forest (Fig. 1).

Sihot' Island represents a relatively small but unique hydrogeological structure with intensive pumping of groundwater by 42 wells situated in different parts of the island. There are 4 wells on Sedláček Island and 34 wells in the Pečniansky forest [1].

This paper is a quantitative analysis of the groundwater flow [2] on these Danube islands and in the Pečniansky forest. It consists of an evaluation of the morphological, 
geological, hydrogeological, and hydrological input data, a quantitative analysis of the groundwater flow regime, and an assessment of potential threats [3] to these water resources due to construction of the multi-purposed structure 'Hydraulic structure Bratislava - Pečniansky forest'.

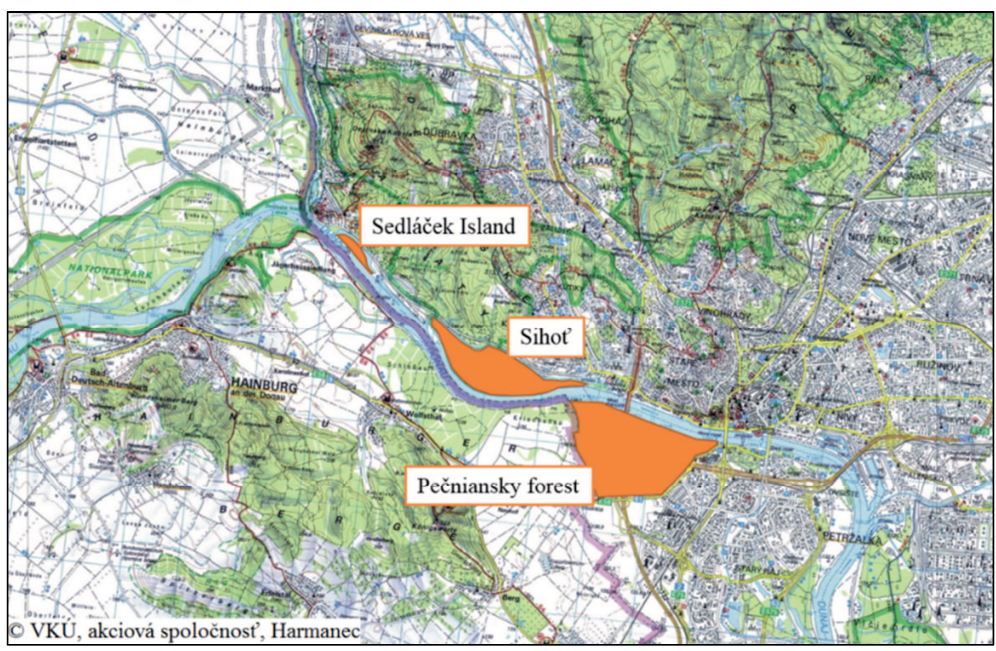

Fig. 1. The area of interest [4]

The location of the proposed Hydraulic Structure (HS) is in Bratislava between the Lafranconi highway bridge and the Austrian border at river kilometer 1872.21 of the Danube River. The HS is an alternative to the Wolfsthal water structure. It consists of a weir in the river and also in the right inundation, nautical structures (two symmetrical lock chambers with upper and lower lock cuts), a hydropower plant, and a bio-corridor at the Karloveské Branch [5].

The issue of the groundwater level regime is dealt by the TRIWACO-Flairs numerical groundwater model, which is based on the finite element method. TRIWACO has been developed by the company Iwaco BV (nowadays Royal Haskoning) [6].

\section{Finite element method}

The finite element method is a numerical method through which any continuous function can be approximated by a discrete model. This model consists of a set of values of the given function (and eventually with its derivatives) at a finite number of preselected points in its domain, together with piecewise approximations of the function over a finite number of connected disjunctive subdomains. These subdomains are called 'finite elements' and are determined by the pre-selected points. The pre-selected points are called 'nodal points' or nodes. The simplest two-dimensional element is a triangular element with three nodes [7]. 
The finite element method may be used to solve Boussinesq's equation, which is a differential equation of the groundwater flow [8],

$$
\mu \frac{\partial h}{\partial t}=k\left[\frac{\partial}{\partial x}\left(H \frac{\partial h}{\partial x}\right)+\frac{\partial}{\partial y}\left(H \frac{\partial h}{\partial y}\right)\right]+v_{0},
$$

where $\mu[-]$ is the active porosity; $h[\mathrm{~m}]$ is the piezometric head; $t[\mathrm{~s}]$ is the time; $k\left[\mathrm{~m} . \mathrm{s}^{-1}\right]$ is the hydraulic conductivity; $H[\mathrm{~m}]$ is the thickness of the saturated medium; $v_{0}\left[\mathrm{~m} . \mathrm{s}^{-1}\right]$ is the infiltration velocity (fictitious value).

\section{Materials and methods}

The modeling protocol can be summarized in the following base steps [9]:

- Step 1, Establishing the purpose of the model;

- Step 2, Developing a conceptual model of the system, which means gathering and evaluating all the source data and materials;

- Step 3, Selecting the governing equation and a computer code. The code is the computer program that contains an algorithm to solve the mathematical model numerically (this was not necessary here, because the TRIWACO groundwater model already contains the necessary equations and the algorithms to solve them);

- Step 4, Designing the model. The conceptual model is put into a form suitable for modeling. This step includes defining the model's boundaries, defining the type and value of the boundary conditions, parameterizing the area, and setting the measured values of the piezometric head in several measurement structures within the field of filtration;

- Step 5, Calibrating the model. The purpose of the calibration is to establish that the model can reproduce field-measured heads and flows. During the calibration a set of values for the aquifer parameters and stresses is found, which approximates the field-measured heads and flows;

- Step 6, The prediction quantifies the response of the system to future events. The model is run with the calibrated values for the parameters and stresses, except for those stresses that are expected to change in the future. Estimates of the future stresses are needed to perform the simulation.

\subsection{Morphological parameters}

To determine the depth of water below the surface of the area (in Paragraph 6) the contour map of the terrain, which is shown in Fig. 2 was constructed. 


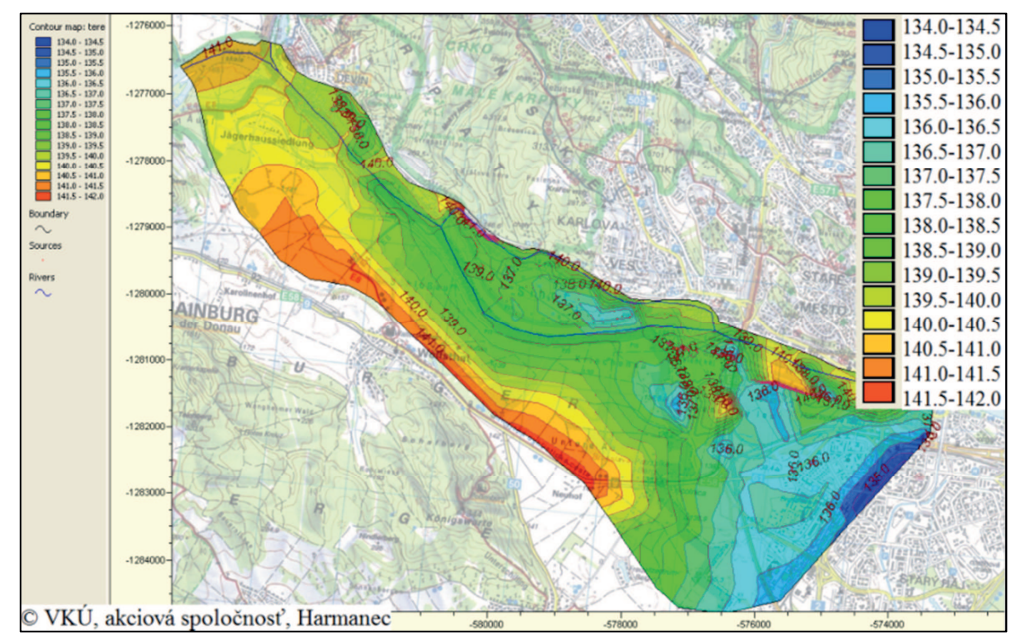

Fig. 2. Contour map of the terrain [4]

\subsection{Geological and hydrogeological parameters}

The term 'geological parameters' represents the top and base of the aquifer [10], and the term 'hydrogeological parameter' represents the hydraulic conductivity $k$ (Table I) [11].

Table I

Geological and hydrogeological parameters

\begin{tabular}{|l|l|c|c|}
\hline Area & Material in aquifer & Thickness $[\mathrm{m}]$ & $k\left[\mathrm{~m}^{-1}\right]$ \\
\hline Sihot' & gravelsand & $6.0-15.0$ & $10^{-1}-10^{-4}$ \\
Sedláček Island & fine and medium-grain sands & $7.2-14.5$ & $10^{-1}-10^{-4}$ \\
& gravelsand & $4.5-11.5$ & \\
Pečniansky forest & sand & $0.0-3.0$ & $1.0-9.6 .10^{-3}$ \\
& gravelsand, gravel & $10.0-14.0$ & \\
\hline
\end{tabular}

In locations where data were not available, these parameters were estimated on the assumption that the geological and even the hydrogeological conditions of the right bank of Austria are similar to the conditions in Petržalka (Slovakia).

\subsection{Hydrological parameters}

The area of interest belongs to the main Danube River Basin. Through the defined field of filtration, the River Morava and Karloveské Branch also flow. To solve the problem, the water level regime for the period from 2011 to 2013 at the stagedischarges of the Vysoká pri Morave and Devínska Nová Ves on the River Morava, and Devín, Bratislava and Rusovce on the Danube River [12] (Fig. 3) were used. 
Also, the measurements of the groundwater level on Sihot' Island and Sedláček Island, and in the Pečniansky forest, and Petržalka [1], [12] (Fig. 4) were used.

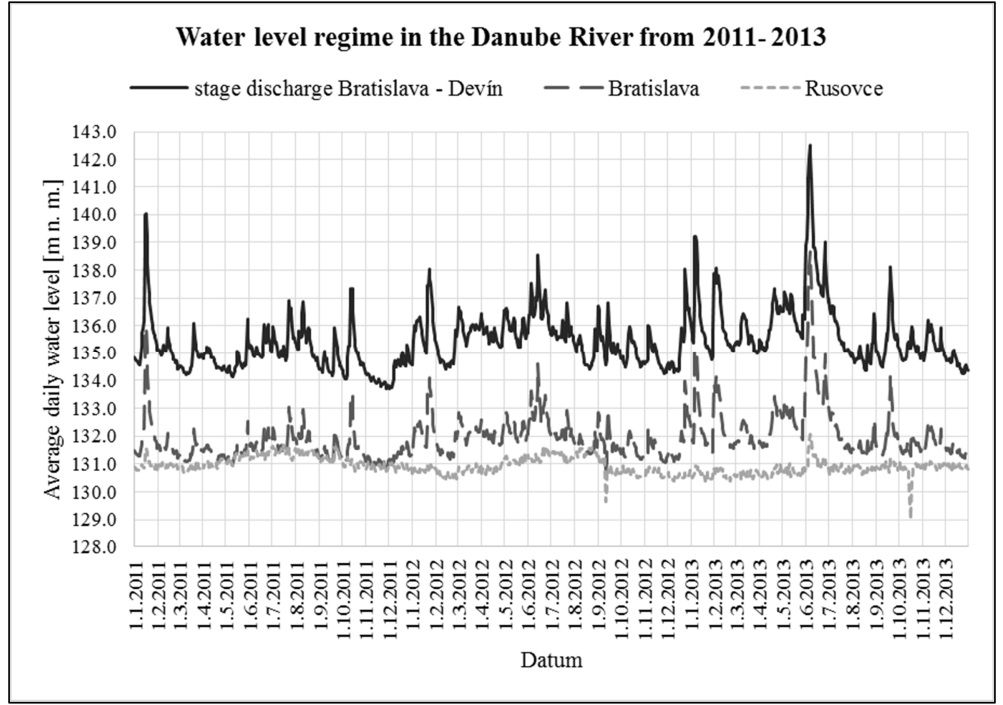

Fig. 3. Water level regime on the Danube River [12]

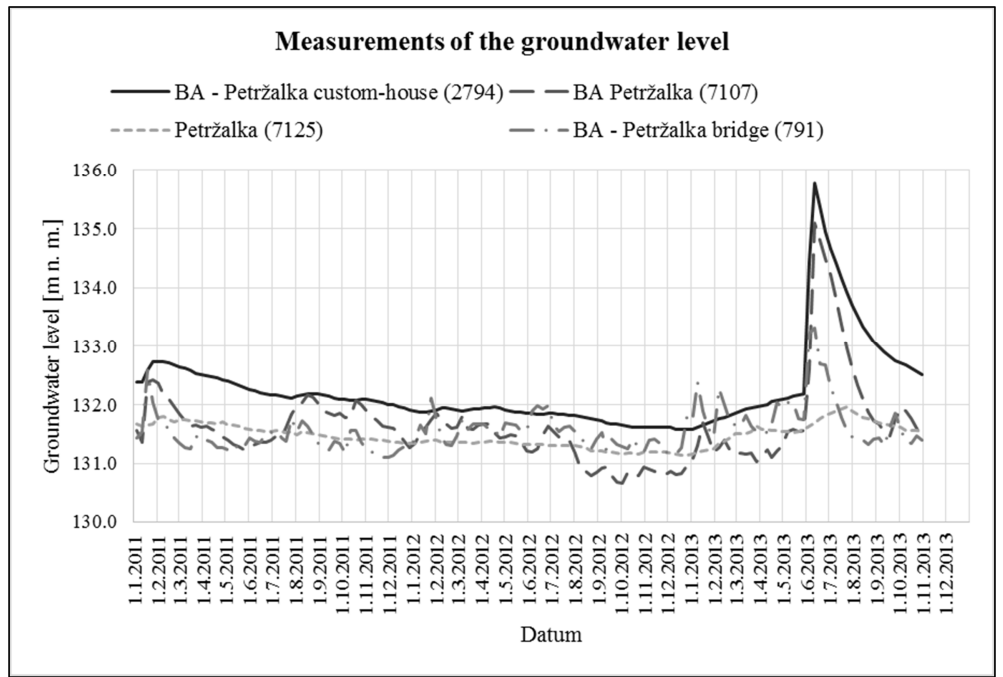

Fig. 4. Groundwater-level measurements [12]

According to the amount of precipitation that falls in the area of interest, this location can be characterized as slightly humid. The average daily rainfall for the mentioned period was $3.2 \mathrm{~mm}$ [12]. However, in terms of the simulation of the 
groundwater, only the effective rainfall is interesting [13]. The effective rainfall is the part of the precipitation totals, which is able to infiltrate into the soil. A raster map of the average values of the effective rainfall for the area of Bratislava was used [14].

The direction of a groundwater flow is also affected by extraction from wells. The medium value of the quantity of the discharges withdrawn from the wells [1] is shown in Table II.

\section{Table II}

Extraction from wells

\begin{tabular}{|l|c|}
\hline Locality & Discharge withdrawn by pumping $\left[1 . \mathrm{s}^{-1}\right]$ \\
\hline Sihot' & 416. \\
Sedláček Island & 24.6 \\
Pečniansky forest & 123.8 \\
\hline
\end{tabular}

\section{Model design}

\subsection{Defining the model boundary and the type of boundary conditions}

The model's boundaries (Fig. 5) are formed in the north by the River Morava and the interfaces of the layers of groundwater bodies in quaternary sediments [15], in the east by the Danube River and the measurement structures of the groundwater level in Petržalka, in the south (in Austria) by the quaternary alluvial deposits of the Danube River, and in the northwest by the Danube River with its confluence with the River Morava.

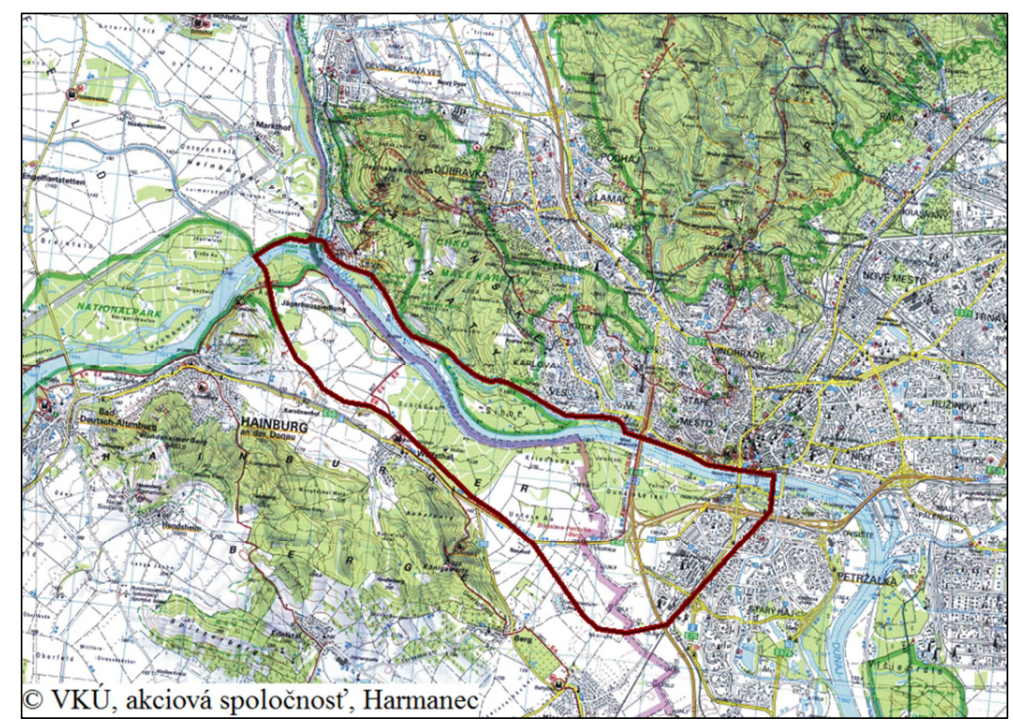

Fig. 5. The model's boundaries [4] 
The boundary conditions were specified as follows:

- the Dirichlet boundary condition specified in the northwest on the Danube and Morava rivers and in the southeast on the Danube River as the water level in the rivers. The water level profiles in the Danube River were simulated using HECRAS [16] and calibrated using measurements of the water levels in the river. On the eastern and southeastern parts of the model's boundaries (in Petržalka), which are formed by the measurement structures of the groundwater levels, the Dirichlet boundary condition has been also specified;

- the Neumann boundary condition with a zero inflow specified in the rest of the model's boundaries.

\subsection{Parameterization of the area}

For the parameterization of the input values, such as the terrain, base and top of the aquifer, and the hydraulic conductivity, the triangular interpolation method (TinInt) was used.

\section{Calibration}

The calibration of the model consisted of setting the hydraulic parameters of the river bed. Those parameters are the values of the hydraulic conductivity and drainage and the infiltration resistance of the rivers [17], [18]. The result of the calibration of the steady-state flow was the groundwater level regime (resp. piezometric head) in the area of interest corresponding to medium hydrological values. The simulation result - a contour map of groundwater levels - is drawn in Fig. 6.

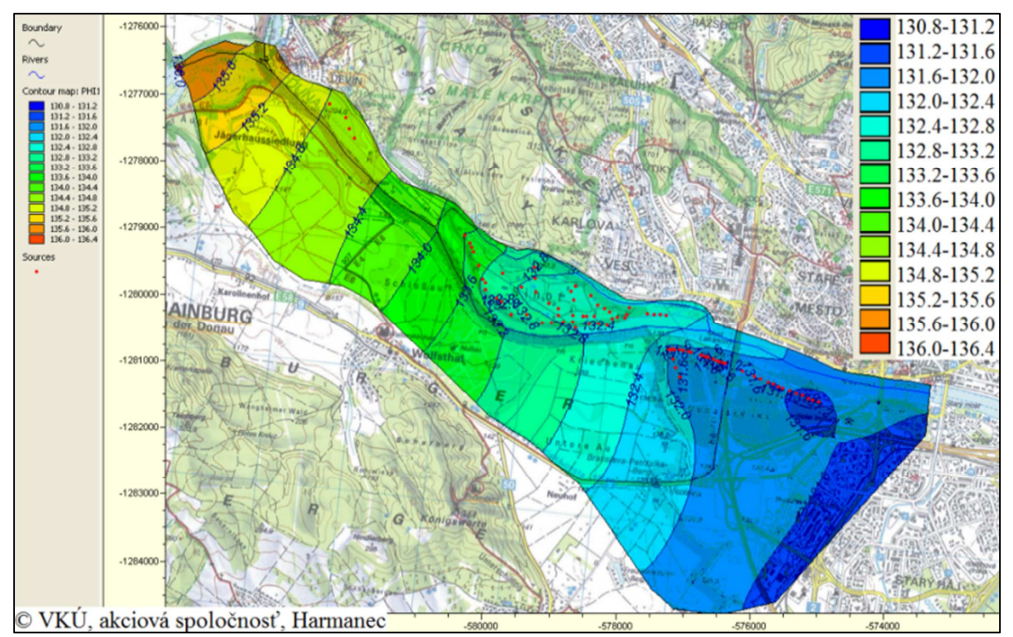

Fig. 6. Groundwater level contour map (m a. s. 1.) - present time [4]

From viewing the groundwater level contour map, it is clear that the groundwater level and the direction of the groundwater flow are directly dependent on the water 
levels in the Danube River [19]. In the vicinity of the wells, however, the level and direction of the groundwater flow is more affected by the pumping of water, especially on Sihot' Island [20] and in the Pečniansky forest, where the pumping is substantially greater than on Sedláček Island.

\section{Simulation of the groundwater level after the construction of the proposed HS}

The result of the simulation, assuming a steady-state flow after the construction of the planned HS, is the groundwater level (or piezometric water level). The isolines of the groundwater level are drawn in Fig. 7. In comparison to the groundwater level at present (Fig. 6), the construction of the HS causes rising of the groundwater level in the backwater area and also changes in the direction of the groundwater flow on Sihot' Island. The reason is that the Karloveské Branch has a function as a bio-corridor and thus influencing the direction of the flow from the Danube River to the branch.

The results of the simulation are also the determination of the depth of the groundwater below the surface and the water level above the terrain, as shown in Fig. 8 . This map was made using the contour map of the terrain.

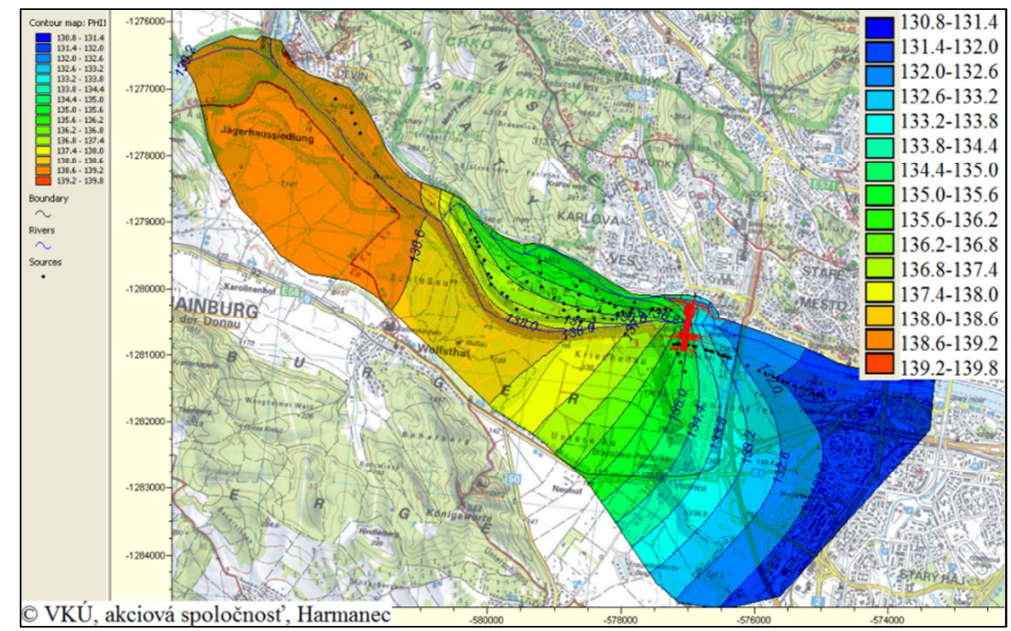

Fig. 7. Groundwater level contour map (m a. s. 1.) - predicted (after HS construction) [4]

From the simulation it is clear that due to the construction of the HS itself, some wells in the Pečniansky forest (with $151 . \mathrm{s}^{-1}$ discharge withdrawn representing $12 \%$ of the capacity of this location) would be destroyed (Fig. 8). The simulation also shows that a part of the Sihot' Island could be flooded, and another part could be waterlogged. Due to the fact that some parts could be flooded, a significant portion of the wells on Sihot' Island (mostly wells near the Danube River) would not be able to be used. The capacity of these wells is $2401 . \mathrm{s}^{-1}$, which represents $58 \%$ of the capacity of Sihot' Island. All the wells could be flooded on Sedláček Island. 


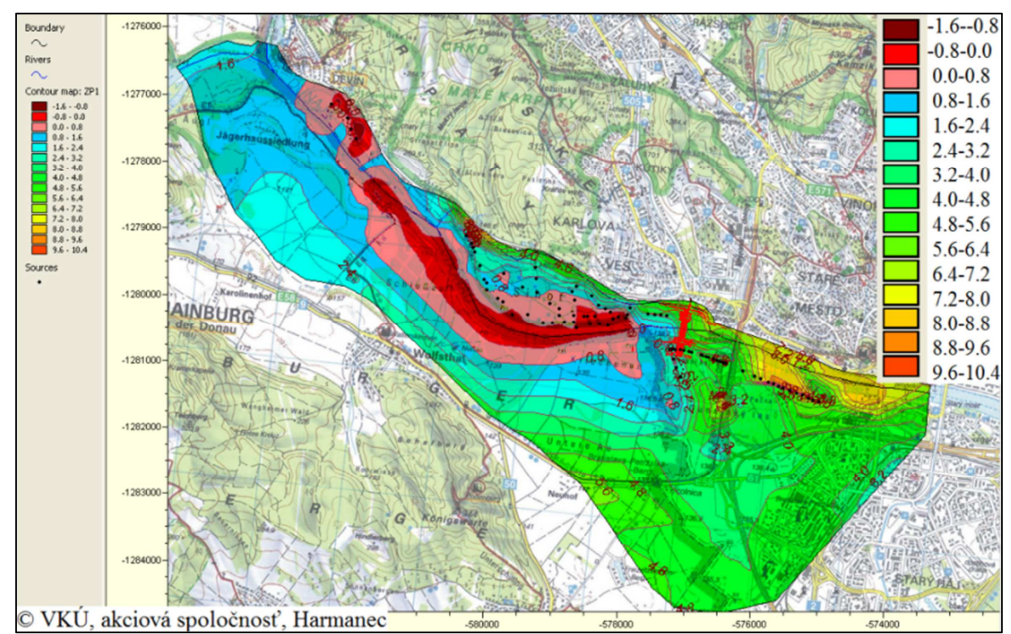

Fig. 8. Depth of groundwater below the surface after the construction of the HS [4]

\section{Conclusion}

There are three main sources of drinking water with satisfactory quality and quantity in Bratislava urban area - the water sources located on the Sihot' and Sedláček inland islands and the water source located in the Pečniansky forest. It is therefore necessary to assess the impact of the proposed construction of the 'Hydraulic structure Bratislava Pečniansky forest' on these water sources.

The results of the simulation show that in terms of maintaining the functions of the water resources, the construction of the HS would be a potential threat to some wells. The groundwater level in the backwater area will rise and thus a part of the Sihot' could be flooded and another part could be waterlogged, so wells in these parts cannot be operated anymore. Moreover all the wells could be flooded on Sedláček Island. Due to the construction itself, some wells in the Pečniansky forest would be destroyed.

For that reason, it is necessary to propose appropriate measures to mitigate or eliminate the negative consequences of the construction of the HS, such as proposals for an underground sealing wall.

\section{Acknowledgements}

This contribution was supported by the VEGA Grant Agency under VEGA Contract $1 / 10011 / 12$.

This publication is the result of the project implementation: 'Centre of Excellence of Integrated Flood protection of Territory', ITMS 26240120004, supported by the Research \& Development Operational Programme funded by the ERDF. 


\section{References}

[1] Source data from Bratislava Water Company, in digital form, 24.11.2014.

[2] Langevin Ch. D., Panday S. Future of groundwater modeling, Groundwater, Vol. 50, No. 3, 2012, pp. 334-339.

[3] Bredehoeft J. D., Konikow L. F. Ground-water models: validate or invalidate, Groundwater, Vol. 50, No. 4, 2012, pp. 493-495.

[4] Tourist atlas of Slovakia M 1:50 000, Detailed tourist map edition (in Slovak) in digital form, Harmanec, VKÚ, š. p, 2005.

[5] Slovák T. Nautical objects of WS Pecensky forest (in Slovak), Diploma Thesis, Faculty of Civil Engineering, Slovak University of Technology in Bratislava. 2010.

[6] Royal Haskoning, Triwaco user's manual, Triwaco 3x, Netherlands, 2004.

[7] Kazda I. Finite element techniques in groundwater flow studies with applications in hydraulic and geotechnical engineering, Elsevier, 1990.

[8] Šoltész A., Baroková D. Hydroinformatics, 2nd part, Simulation of processes of groundwater flow in porous media, (in Slovak), Faculty of Civil Engineering, Slovak University of Technology in Bratislava, 2010.

[9] Anderson M., Woessner W. Applied groundwater modeling, Simulation of flow and advective transport, California, Academic Press, 1992.

[10] Sheets R. A., Hill M. C., Haitjema H. M., Provost A. M., Masterson J. P. Simulation of water-table aquifers using specified saturated thickness, Groundwater, Vol. 53, No. 1, 2015, pp. 151-157.

[11] Kozma Z., Ács T., Koncsos L. Hydrological modeling of the unsaturated zone, Evaluation of uncertainties related to the FAO soil classification system, Pollack Periodica, Vol. 8, No. 3, 2013, pp. 163-174.

[12] Source data from Slovak Hydrometeorological Institute, in digital form, 27.2.2015.

[13] Pelikán P., Šlezingr M. Methodology for the establishment of physical and geometric properties of a drainage basin, Acta Universitatis Agriculturae et Silviculturae Mendelianae Brunensis, Vol. 59, No. 6, 2011, pp. 265-270.

[14] Švasta J., Malík P. Spatial distribution of mean effective precipitation over Slovakia (in Slovak), Podzemná voda, Vol. XII, No. 1, 2006, pp. 65-77.

[15] Kullman E., Malík P., Patschová A., Bodiš D. Delinaeation of groundwater bodies on Slovak territory according to EU Water Framework Directive 2000/60/EC (in Slovak), Podzemná voda, Vol XI, No. 5, 2005, pp. 5-18.

[16] Brunner G. W. HEC-RAS, River analysis system user's manual, Version 4.1. Davis, CA, US Army Corps of Engineers, Hydrologic Engineering Centre, 2010.

[17] Zaadnoordijk W. J. Simulating piecewise-linear surface water and ground water interactions with MODFLOW, Groundwater, Vol. 47, No. 5, 2009, pp. 723-726.

[18] Velísková Y., Koczka Bara M., Dulovičová R., Schügerl R. Influence of surface water level fluctuation and riverbed sediment deposits on groundwater regime, Journal of Hydrology and Hydromechanics, Vol. 62, No. 3, 2014, pp. 177-185.

[19] Šoltész A., Baroková D. Analysis of surface and ground water interaction in the Danube River branch system, Proc. of 14th International Multidisciplinary Scientific Geoconference and EXPO, Vol. 1, No. 3, Albena, Bulgaria, 17-26 June, 2014, pp. 51-58.

[20] Andrássy T., Baroková D. Numerical modeling of groundwater flow close to drinking water resources during flood events, Pollack Periodica, Vol. 11, No. 1, 2016, pp. 43-54. 